www.jmscr.igmpublication.org

Impact Factor 5.244

Index Copernicus Value: 5.88

ISSN (e)-2347-176x ISSN (p) 2455-0450

crossref DOI:_http://dx.doi.org/10.18535/jmscr/v4i5.10

Journal Of Medical Science And Clinical Research

\title{
A Study to Establish the Validity of Non-Fasting Lipid Profile against Fasting Lipid Profile for Making Treatment Decision in Diabetes Mellitus 2012-2014
}

\author{
Authors \\ Lokesh Gupta, Vipan Kumar Goyal, Amit Baweja \\ Department of medicine, Mata Chanan Devi Hospital, Janakpuri, New Delhi
}

\begin{abstract}
As incidence of diabetes is continuously increasing in india and diabetic dyslipidemia is a leading cause of atherosclerotic disease process like coronary artery disease. If we diagnosed and treat dyslipidemia in early stage, we can decrese the risk of atherosclerotic diseases. But current guidelines recommend measurement of fasting lipid profile and majority of the patients present in the hospital are in nonfasting state so their lipid profile is deferred due to their nonfasting status which impedes their treatment. However, recent studies suggest nonfasting lipid profile may better or similarly predict cardiovascular disease events than fasting levels. So, if validate for treatment of diabetic dyslipidemia then measurement of nonfasting lipid profile may have many practical advantage for clinical practice. So a prospective study was carried out in 100 diabetic patients in 25-65 years age group including both sexes irrespective of community or background which were present in inpatient department of medicine, Mata Chanan Devi hospital, New Delhi, during the time period of 2012-2014. It is a 210 bedded, tertiary care hospital in west Delhi, where the patients travel from all north India. The patients with Coronary event (myocardial infarction, unstable angina) and procedures (coronary artery bypass, coronary angioplasty) in previous 4 weeks, ischemic stroke in prior 3 months, chronic alcoholic patients, patients having pancreatitis, hypothyroidism, pregnancy and patients on lipid lowering drugs in previous 3 months, were not included in the study. After taking written informed consent lipid profile was done from each subject at the time of admission and next day morning (after 8-12 hr fasting). Self reported time since last meal was also noted at the time of admission. LDL was measured by direct method. Non HDL cholesterol was calculated by total cholesterol - HDL cholesterol. SPSS (statistical package for social sciences) software version 16.0 was used for statistical analysis. Wilcoxon Signed Ranks test done to compare the total mean fasting and nonfasting lipid profile. We divided the study subjects according to self reported time since last meal. Like 0-1 hour include patient taking meal before $<1$ hour and 1-2 hour include <2 hour post meal and so on other groups. Comparison of fasting and non fasting lipid profile was done by Wilcoxon Signed Ranks Test in all groups. All P values were 2-tailed. $P$ value $<0.05$ is statistical significant.

Salient findings Out of 100 patients, there were 44 females and 56 males subjects. Minimum age is 32 years and maximum age is 65 years. Mean age in males is $56.12 \pm 8.05$ and in females $57.91 \pm 7.13$. Incidence of
\end{abstract}




\section{JMSCR Vol||04||Issue||05||Page 10432-10443||May}

diabetes was higher in >50 years of age group and among males. 15 out of 100 diabetic subjects were on insulin therapy and rest 85 were on Oral hypoglycemic drugs only. Out of 100 diabetic patients 45 were hypertensive, 7 CAD, 9 CKD and 10 had history of CVA. Mean fasting blood sugar was 112.26mg/dl and mean post prandial blood sugar was $192.65 \mathrm{mg} / \mathrm{dl}$ as patients were on treatment for diabetes. Mean HbAlc among females was $7.54 \pm 1.39$ and in males was $7.79 \pm 1.48$. The mean total cholesterol level in the 100 diabetic patients included in the study in the fasting state was $166.48 \pm 45.30 \mathrm{mg} / \mathrm{dl}$, and in the non-fasting state it was $167.06 \pm 46.03 \mathrm{mg} / \mathrm{dl}$, the $p$ value was more than $>0.05$ thus making it statistically insignificant. The mean HDL level in the fasting state was $38.93 \pm 13.72 \mathrm{mg} / \mathrm{dl}$, and in the non-fasting state it $38.67 \pm 13.30 \mathrm{mg} / \mathrm{dl}$, the $p$ value is $>0.05$, making it statistically insignificant. The mean direct LDL level in the fasting state was $86.41 \pm 34.90 \mathrm{mg} / \mathrm{dl}$ and in the non-fasting state it was $86.35 \pm 38.38 \mathrm{mg} / \mathrm{dl}$, the $p$ value again $>0.05$, making it statistically insignificant. The mean triglyceride level in the fasting state was $184.82 \pm 29.26 \mathrm{mg} / \mathrm{dl}$ and in the non-fasting state it was 205.87 $\pm 31.83 \mathrm{mg} / \mathrm{dl}$, it is higher in the nonfasting group and the $p$ value is $<0.05$, which is statistically significant. The mean non HDL level in the fasting state was $127.55 \pm 43.06 \mathrm{mg} / \mathrm{dl}$ and in the non-fasting state it was $128.38 \pm 43.21 \mathrm{mg} / \mathrm{dl}$, the $p$ value $>0.05$, making it statistically insignificant Comparison of nonfasting and fasting lipid profile according to time since last meal Post meal values of total cholesterol, HDL cholesterol, direct LDL cholesterol, non HDL cholesterol and triglycerides correlate with their fasting values. There was no significant difference in fasting and nonfasting total cholesterol, HDL $c$, direct LDL $c$ and non HDLc as a function of time since last meal. Triglycerides is significantly increased up to 6-7 hour after meal as $p$ value is $<0.05$. Although it is higher in nonfasting even after 6-7 hours but statistically insignificant. The highest increased in levels of triglycerides were noted 3 to 5 hour after meal.

Conclusion- Difference between nonfasting and fasting values of total cholesterol, HDL cholesterol, direct LDL cholesterol and non HDL cholesterol were statistically insignificant. Triglycerides values were significantly high in non-fasting state. Post meal level of all lipids and lipoproteins correlate with their fasting values in the different groups of time since last meal. Triglycerides were increase after meal and maximum increased from fasting was seen 3 to 5 hours after meal. Total cholesterol, HDL cholesterol, direct LDL cholesterol and non HDL cholesterol differ insignificantly from their fasting values as a function of time since last meal. In our study level of lipids differed minimally in nonfasting. We measured direct LDL which differed insignificantly from fasting direct $L D L$. Calculated $L D L$ can underestimate after meal as elevated triglycerides in Friedewald formula $(L D L c=T C-H D L c-T G / 5)$. In our study higher nonfasting than fasting triglycerides were likely attributable directly to fat intake. And recent studies suggest nonfasting or postprandial hypertriglyceridemia is a significant risk factor for atherosclerosis. From above findings we conclude that nonfasting blood draws may be highly effective and practical for lipid profile testing in diabetic patients. Recommendations- Lipid profile can be done in nonfasting state in diabetics and it is more practical and more feasible as we spend our maximum time in nonfasting state. LDL should be done by direct method as in nonfasting state increased triglycerides can underestimate the calculated LDL by Friedewald formula. Non $H D L$ cholesterol can be measured in nonfasting state. More recently this is studied for better predictor of cardiovascular risk than LDL because it includes all Apo-B containing atherogenic lipoproteins. Future research should focus on studies reducing the levels of nonfasting triglycerides and thus remnant lipoprotein cholesterol in an attempt to reduce the risk of cardiovascular disease and death further than that currently obtained by reducing mainly LDL cholesterol levels. Furthermore the results also highlight the need for randomized double blind trials of new and established drugs to reduce nonfasting triglycerides and remnant lipoprotein cholesterol, with the ultimate aim of reducing risk of cardiovascular disease and early death.

\section{Introduction}

Diabetes is on rising trend in India and diabetic dyslipidemia is a leading cause of atherosclerotic

disease process like coronary artery disease. If we diagnosed and treat dyslipidemia in early stage, 
we can decrese the risk of atherosclerotic diseases. At present NCEP ATP III guidelines allow to measure the total and HDL cholesterol in nonfasting state, as the level of these two lipids altered minimally when measured in fasting and non-fasting state ${ }^{1}$. However non HDL cholesterol, a secondary target of therapy in Adult Treatment Panel III may also be measure in non fasting state. Diabetes itself does not increase the level of LDL, but the small dense LDL particles found in type 2 DM are more atherogenic because they are more easily glycated and susceptible to oxidation. So type 2 diabetic patients have markedly increased risk of CHD than non-diabetic subjects who may have similar dyslipidemia ${ }^{2}$. It has also been reported that magnitude and duration of postprandial lipidaemia is positively related to the pathogenesis and progression of $\mathrm{CHD}^{3-5}$. However, recent studies suggest nonfasting lipid profile may better or similarly predict cardiovascular disease events than fasting levels ${ }^{6-}$ 7. So, if validate for treatment of diabetic dyslipidemia then measurement of nonfasting lipid profile may have many practical advantage for clinical practice. as majority of the patients present in the hospital are in nonfasting state so their lipid profile is deferred due to their nonfasting status which impedes their treatment.

\section{Objective}

Our aim was to find out, if there is any significant difference between fasting and non-fasting lipid profiles in diabetic patients. And if not then to validate the nonfasting lipid profile for making treatment decision in treatment of diabetic dyslipidemia.

\section{Materials and method}

A prospective study was carried out in 100 diabetic patients in 25-65 years age group including both sexes irrespective of community or background which were present in inpatient department of medicine, Mata Chanan Devi hospital, New Delhi, during the time period of 2012-2014. The patients with Coronary event (myocardial infarction, unstable angina) and procedures (coronary artery bypass, coronary angioplasty) in previous 4 weeks, ischemic stroke in prior 3 months, chronic alcoholic patients, patients having pancreatitis, hypothyroidism, pregnancy and patients on lipid lowering drugs in previous 3 months, were not included in the study. Diabetes is a self reported disease. The diagnosis of diabetes is based on American diabetic association criteria. Before starting the study, permission was taken from institutional ethical committee. A written informed consent was taken. A detailed history was taken and careful physical examination was done. Lipid profile was done from each subject at the time of admission and next day morning (after 8-12 hr fasting). Self reported time, since last meal was also noted at the time of admission. Other baseline investigation like haematological profile, blood urea, serum creatinine, serum aminotransferase, serum uric acid, serum electrolytes was also carried out at the time of admission. LDL was measured by direct method. Blood sugar was analysed using hexokinase method. All the data and various findings including the past history, present diagnosis, blood sugar, HbA1c, nonfasting and fasting lipid profile of all subjects were tabulated and evaluated using Microsoft Excel. Non HDL cholesterol was calculated by total cholesterol - HDL cholesterol.

SPSS (statistical package for social sciences) software version 16.0 was used for statistical analysis. Pearson Chi-Square test is done for Sex distribution in different age group and in different HbA1C categories. Wilcoxon Signed Ranks a Non Parametric test was done because there was skewed deviation in variables, so parametric Student t- test could not be applicable for comparison. However, results were similar by paired Student t- test also. Wilcoxon Signed Ranks test done to compare the total mean fasting and nonfasting lipid profile. Study subjects were divided according to self reported time since last meal. 0-1 hour period include patients taken meal $<1$ hour before, 1-2 hour include <2 hour after 
meal and as so on. To compare as a function of time since last meal, comparison of fasting and non fasting lipid profile was done separately in all groups by Wilcoxon Signed Ranks Test. All P values were 2 -tailed. $\mathrm{P}$ value $<0.05$ is statistical significant.

\section{Result}

Out of 100 patients, there were 44 females and 56 males' subjects. Minimum age is 32 years and maximum age is 65 years. Mean age in males is $56.12 \pm 8.05$ and in females $57.91 \pm 7.13$. Incidence of diabetes was higher in $>50$ years of age group and among males. Out of 100 patients, 85 were only on oral hypoglycemic agents and rest also taking insulin therapy. Mean fasting blood sugar was $112.26 \mathrm{mg} / \mathrm{dl}$ and mean post prandial blood sugar was $192.65 \mathrm{mg} / \mathrm{dl}$ as patients were on treatment for diabetes. Mean HbA1c among females was $7.54 \pm 1.39$ and in males was $7.79 \pm 1.48$.

The mean total cholesterol level in the 100 diabetic patients included in the study in the fasting state was $166.48 \pm 45.30 \mathrm{mg} / \mathrm{dl}$, and in the non-fasting state it was $167.06 \pm$

$46.03 \mathrm{mg} / \mathrm{dl}$, the $\mathrm{p}$ value was more than $>0.05$ thus making it statistically insignificant.

The mean HDL level in the fasting state was $38.93 \pm 13.72 \mathrm{mg} / \mathrm{dl}$, and in the non-fasting state it was $38.67 \pm 13.30 \mathrm{mg} / \mathrm{dl}$, the $\mathrm{p}$ value is $>0.05$, making it statistically insignificant.
The mean direct LDL level in the fasting state was $86.41 \pm 34.90 \mathrm{mg} / \mathrm{dl}$ and in the non-fasting state it was $86.35 \pm 38.38 \mathrm{mg} / \mathrm{dl}$, the $\mathrm{p}$ value again $>0.05$, making it statistically insignificant.

The mean triglyceride level in the fasting state was $184.82 \pm 29.26 \mathrm{mg} / \mathrm{dl}$ and in the non-fasting state it was $205.87 \pm 31.83 \mathrm{mg} / \mathrm{dl}$, it is higher in the nonfasting group and the $\mathrm{p}$ value is $<0.05$, which is statistically significant.

The mean non HDL level in the fasting state was $127.55 \pm 43.06 \mathrm{mg} / \mathrm{dl}$ and in the non-fasting state it was $128.38 \pm 43.21 \mathrm{mg} / \mathrm{dl}$, the $\mathrm{p}$ value $>0.05$, making it statistically insignificant

\section{Comparison of nonfasting and fasting lipid profile according to the time since last meal}

- Post meal values of total cholesterol, HDL cholesterol, direct LDL cholesterol, non HDL cholesterol and triglycerides correlate with their fasting values.

- Triglycerides was significantly increased up to 6-7hour after meal as $\mathrm{p}$ value was $<0.05$. Although it was higher in nonfasting even after 6-7 hours but statistically insignificant.

- The highest increased in levels of triglycerides were noted 3 to 5 hour after meal.

- There was no significant difference in fasting and nonfasting total cholesterol, HDL $\mathrm{c}$, direct LDL $\mathrm{c}$ and non HDL $\mathrm{c}$ as a function of time since last meal as $\mathrm{p}$ value $>0.05$.

Table 1- distribution of study subjects according to age and sex

\begin{tabular}{|l|c|c|c|}
\hline Age in years & Male & Female & Total \\
\hline$<40$ & 4 & 1 & 5 \\
\hline $41-50$ & 7 & 7 & 14 \\
\hline $51-60$ & 24 & 17 & 41 \\
\hline$>60$ & 21 & 19 & 40 \\
\hline Total & 56 & 44 & 100 \\
\hline Mean \pm SD & $56.12 \pm 8.05$ & $57.91 \pm 7.13$ & $56.91 \pm 7.67$ \\
\hline
\end{tabular}


Table 2- total mean fasting and non fasting lipid profile of 100 patients

\begin{tabular}{|c|c|c|c|c|c|}
\hline \multirow{2}{*}{ Lipid profile } & \multicolumn{2}{|c|}{ FASTING LEVELS } & \multicolumn{2}{|c|}{$\begin{array}{c}\text { NON-FASTING } \\
\text { LEVELS }\end{array}$} & \multirow{2}{*}{$\begin{array}{c}\mathrm{p} \\
\text { value }\end{array}$} \\
\hline & Mean \pm SD & $\begin{array}{l}\text { Min - } \\
\text { Max }\end{array}$ & Mean \pm SD & $\begin{array}{c}\text { Min - } \\
\text { Max }\end{array}$ & \\
\hline Total Cholesterol & $166.48 \pm 45.30$ & $81-296$ & $167.06 \pm 46.03$ & $57-281$ & 0.746 \\
\hline HDL & $38.93 \pm 13.72$ & $18-95$ & $38.67 \pm 13.30$ & $14-89$ & 0.443 \\
\hline$\overline{L D L}$ & $86.41 \pm 34.90$ & $13-205$ & $86.35 \pm 38.38$ & $17-195$ & 0.882 \\
\hline Non HDL & $127.55 \pm 43.06$ & $52-238$ & $128.38 \pm 43.21$ & $43-242$ & 0.652 \\
\hline Triglycerides & $184.82 \pm 29.26$ & $153-287$ & $205.87 \pm 31.83$ & $164-316$ & 0.000 \\
\hline
\end{tabular}

Table 3- Mean fasting and nonfasting total cholesterol in different groups of time since last meal

\begin{tabular}{|l|c|c|c|c|}
\hline $\begin{array}{l}\text { Time since last } \\
\text { meal (hour) }\end{array}$ & No. of patients & TCH (R) & TCH (F) & P value \\
\hline $0-1$ & 10 & 229.8 & 215.2 & 0.308 \\
\hline $1-2$ & 5 & 179 & 180.2 & 0.786 \\
\hline $2-3$ & 18 & 175.5 & 180.83 & 0.231 \\
\hline $3-4$ & 22 & 171.32 & 171.77 & 0.543 \\
\hline $4-5$ & 6 & 151.5 & 136.67 & 0.093 \\
\hline $5-6$ & 11 & 146 & 146.82 & 0.878 \\
\hline $6-7$ & 24 & 147.08 & 148.58 & 0.897 \\
\hline $7-8$ & 1 & 161 & 175 & - \\
\hline $8-9$ & 1 & 143 & 147 & - \\
\hline $9-10$ & 2 & 118 & 119 & 0.655 \\
\hline Total & 100 & 167.06 & 166.48 & 0.746 \\
\hline
\end{tabular}


Table 4- Mean fasting and nonfasting triglycerides in different groups of time since last meal

\begin{tabular}{|l|c|c|c|c|}
\hline $\begin{array}{l}\text { Time since last } \\
\text { meal (hour) }\end{array}$ & No. of patients & TG (R) & TG (F) & P value \\
\hline $0-1$ & 10 & 214.4 & 192.6 & 0.005 \\
\hline $1-2$ & 5 & 214.8 & 193.8 & 0.043 \\
\hline $2-3$ & 18 & 212.77 & 189.22 & 0.000 \\
\hline $3-4$ & 22 & 206.04 & 182.9 & 0.000 \\
\hline $4-5$ & 6 & 206 & 182.5 & 0.027 \\
\hline $5-6$ & 11 & 204.09 & 181.18 & 0.003 \\
\hline $6-7$ & 24 & 198.41 & 181.54 & 0.000 \\
\hline $7-8$ & 1 & 196 & 181 & - \\
\hline $8-9$ & 1 & 193 & 179 & - \\
\hline $9-10$ & 2 & 187 & 176 & 0.180 \\
\hline Total & 100 & 205.87 & 184.22 & 0.000 \\
\hline
\end{tabular}

Table 5- Mean fasting and nonfasting HDL cholesterol in different groups of time since last meal

\begin{tabular}{|l|c|c|c|c|}
\hline $\begin{array}{l}\text { Time since last } \\
\text { meal (hour) }\end{array}$ & No. of patients & HDL (R) & HDL (F) & P value \\
\hline $0-1$ & 10 & 38.9 & 38.8 & 0.683 \\
\hline $1-2$ & 5 & 38.8 & 37.8 & 0.581 \\
\hline $2-3$ & 18 & 39.44 & 39.56 & 0.905 \\
\hline $3-4$ & 22 & 39.55 & 38.23 & 0.119 \\
\hline $4-5$ & 6 & 35.67 & 40.17 & 1.000 \\
\hline $5-6$ & 11 & 39.18 & 38.27 & 0.474 \\
\hline $6-7$ & 24 & 37.42 & 39.17 & 0.196 \\
\hline $7-8$ & 1 & 49 & 47 & - \\
\hline $8-9$ & 1 & 31 & 31 & - \\
\hline $9-10$ & 2 & 40.5 & 41.5 & 0.655 \\
\hline Total & 100 & 38.67 & 38.93 & 0.443 \\
\hline
\end{tabular}

Table 6- Mean fasting and nonfasting LDL cholesterol in different groups of time since last meal

\begin{tabular}{|l|c|c|c|c|}
\hline $\begin{array}{l}\text { Time since last } \\
\text { meal (hour) }\end{array}$ & No. of patients & LDL (R) & LDL (F) & P value \\
\hline $0-1$ & 10 & 134.6 & 111 & 0.057 \\
\hline $1-2$ & 5 & 84 & 81 & 0.893 \\
\hline $2-3$ & 18 & 87.56 & 98.17 & 0.093 \\
\hline $3-4$ & 22 & 87.05 & 90.55 & 0.256 \\
\hline $4-5$ & 6 & 81.5 & 69 & 0.075 \\
\hline $5-6$ & 11 & 71 & 73.18 & 0.533 \\
\hline $6-7$ & 24 & 76.12 & 77.33 & 0.603 \\
\hline $7-8$ & 1 & 91 & 98 & - \\
\hline $8-9$ & 1 & 87 & 90 & - \\
\hline $9-10$ & 2 & 51.5 & 52 & 0.655 \\
\hline Total & 100 & 86.35 & 86.41 & 0.882 \\
\hline
\end{tabular}


Table 7- Mean fasting and nonfasting non HDL cholesterol in different groups of time since last meal

\begin{tabular}{|l|c|c|c|c|}
\hline $\begin{array}{l}\text { Time since last } \\
\text { meal (hour) }\end{array}$ & No. of patients & Non HDL (R) & Non HDL (F) & P value \\
\hline $0-1$ & 10 & 190.9 & 176.4 & 0.285 \\
\hline $1-2$ & 5 & 140.2 & 142.4 & 0.686 \\
\hline $2-3$ & 18 & 136.06 & 141.28 & 0.246 \\
\hline $3-4$ & 22 & 131.72 & 133.55 & 0.807 \\
\hline $4-5$ & 6 & 115.83 & 96.5 & 0.072 \\
\hline $5-6$ & 11 & 106.82 & 108.55 & 0.594 \\
\hline $6-7$ & 24 & 109.67 & 109.42 & 0.592 \\
\hline $7-8$ & 1 & 112 & 128 & - \\
\hline $8-9$ & 1 & 112 & 116 & - \\
\hline $9-10$ & 2 & 77.5 & 77.5 & 1 \\
\hline Total & 100 & 128.38 & 127.55 & 0.652 \\
\hline
\end{tabular}

\section{Discussion}

In a study Alsaran $\mathrm{K}$ et $\mathrm{al}^{8}$ (2009) included one hundred seventy two patients, in which ninety five male patients $(55.2 \%)$ and seventy seven female patients $(44.8 \%)$ and their mean age was $49.98 \pm$ 15.66 years. In this study there was no significant difference between total cholesterol, LDL and HDL cholesterol measured in the fasting and nonfasting state $(3.89 \pm .88$ versus $3.96 \pm 0.96(\mathrm{mmol} / \mathrm{l})$, $\mathrm{p}=0.01),(2.05 \pm .61$ versus $2.09 \pm 0.67(\mathrm{mmol} / \mathrm{l})$, $\mathrm{p}=.32), \quad(0.94 \pm .32$ versus $0.91 \pm 0.26 \quad(\mathrm{mmol} / \mathrm{l})$, $\mathrm{p}=0.08$ ) respectively. However, non-fasting triglycerides were significantly higher than fasting levels $(1.75 \pm 1.08$ versus $1.52 \pm 0.89 \quad(\mathrm{mmol} / \mathrm{l})$, $\mathrm{p}=0.000$ ). There was a strong positive correlation between fasting and non-fasting non- HDL ( R square $=0.77, p=0.005)$. The same finding was observed in both diabetics and non-diabetics. In the study done by Lee $\mathrm{SH}$ et $\mathrm{al}^{9}$ the mean age of the subjects were $57.7 \pm 11.2$ years and sex distribution showed that there were more diabetic males $59 \%$ compared to diabetic females $41 \%$. In our study the number of males was $56(56 \%)$ and number of females was $44(44 \%)$ and mean age was $56.91 \pm 7.67$ years. Mean age among males was $56.12 \pm 8.05$ years and in females was 57.91 \pm 7.13 years.

In a study by Desmueles $S$ et $a^{10}$ (2005) there was a $10 \%$ elevation in TG levels and an apparent reduction in HDL (6.9\%), c LDL (5.3\%), and TC $(2.3 \%)$ levels in the nonfasting state. Except for
TG, the correlation between fasting and nonfasting results seems acceptable considering biological and analytical variations. Non- HDL cholesterol level showed the greatest correlation and an absolute relative difference of $5.7 \%$. In a study by Kimak E et al ${ }^{11}$ (2007) Regression and Bland-Altman analyses showed excellent correlation between fasting and nonfasting nonHDL-C levels $(r=0.987, \mathrm{R}(2)+0.987)$ in post renal transplant patients both with dyslipidemia and normolipidemic. In a study by Mora $\mathrm{S}$ et $\mathrm{al}^{12}$ (2008) except triglycerides, all other lipids and lipoproteins differed minimally when measured in nonfasting in compared to fasting. Triglycerides were higher in nonfasting. In a study by Dungan KM et $\mathrm{al}^{13}$ (2007) of 31 diabetic patients, only $56 \%$ of LDLc measurements were equivalent in the fasting and nonfasting states, compared to $97 \%$ of Direct LDLc ( $p<0.0001$ ), $94 \%$ of non-HDLc $(\mathrm{p}<0.001)$ and $77 \%$ of LDLP $(\mathrm{p}<0.01)$ measurements. Schaefer EJ et $\mathrm{al}^{14}$ (2001) study suggests it is not necessary to obtain a fasting sample to assess direct LDL and HDL cholesterol. Craig SR et al $^{15}$ (2000) observed clinically insignificant difference in fasting and nonfasting total cholesterol. Nonfasting HDL c levels were similar to fasting HDL c. They suggest screening nonfasting adults for total and HDL cholesterol is appropriate for making decision about primary prevention of coronary artery disease. In our study there was no 
significant difference between total mean fasting and nonfasting values of 100 diabetic subjects for total cholesterol, HDL cholesterol, direct LDL cholesterol and non HDL cholesterol as p value for these >0.05. However nonfasting triglycerides is significantly higher than fasting as $\mathrm{p}$ value is $<0.05$.

\section{Time since last meal ${ }^{6,7,31,32,34-38,40,41-43}$. \\ $8,12,16,18,21,23,27-30$ is a}

We compare the fasting lipids with nonfasting as a function of time since last meal by dividing the study subjects according to self reported post meal time. Study done by Mora S et al ${ }^{12}$ (2008) showed that except for triglycerides, there were no substantial changes in the distributions of lipids as a function of time since last meal. Triglycerides increased after meal. The highest levels of triglycerides were noted 4-5 hour after meal. Lipid concentrations differed minimally $(<5 \%)$ for fasting versus nonfasting. Langested $\mathrm{A}$ et $\mathrm{al}^{16}$ (2008) showed compared with fasting levels, total cholesterol, HDL cholesterol, LDL cholesterol and albumin levels were reduced up to 3 to 5 hour after meal; triglycerides levels were increased up to 6 hours after the last meal. And non HDL cholesterol level did not change in response to normal food intake. Reduced levels of albumin after normal food intake are likely caused by hemodilution resulting from fluid intake. Therefore adjustment for albumin was done. After this adjustment total cholesterol, LDL cholesterol no longer differed as a function of time since last meal. Wilder LB et $\mathrm{al}^{17}$ (1995) studied 115 subjects, found triglycerides increased and total cholesterol and HDL remains unchanged 3-5 hour after a normal breakfast compared with fasting levels. Sidhu D et al $^{18}$ (2012) studied the fasting time and lipid levels in a community based population showed the mean levels of total cholesterol and high-density lipoprotein cholesterol differed little among individuals with various fasting times. The mean calculated lowdensity lipoprotein cholesterol levels showed slightly greater variations of up to $10 \%$ among groups of patients with different fasting intervals, and the mean triglyceride levels showed variations of up to $20 \%$. Steiner MJ et al ${ }^{19}$ (2011) studied the fasting and nonfasting lipid levels. There were only small changes in lipid components based on hours of fasting, although values for all measurements except non HDL cholesterol did reach statistical significance. Levels LDL increase and triglycerides decrease with the time. While those for total cholesterol, HDL and non HDL cholesterol not show a dramatic change over time. In our study post meal levels of all lipids correlate with their fasting values in the different groups of time since last meal. Triglycerides were higher in nonfasting when compared with fasting. Triglycerides was significantly increased up to 6-7 hour after meal as $\mathrm{p}$ value $<0.05$. And maximum increased from fasting was 3 to 5 hours after meal. Levels of other lipids like total cholesterol, HDL cholesterol, direct LDL cholesterol and non HDL cholesterol differed insignificantly from their fasting values as $\mathrm{p}$ value $>0.05$.

Our findings show that levels of lipids and lipoproteins after normal food intake differ only minimally from levels in the fasting state ${ }^{12,14,19,20}$, probably because most people consume much less fat at ordinary meals than during a fat tolerance test which includes $1 \mathrm{gm}$ fat per $\mathrm{kg}$ body weight. Total cholesterol ${ }^{8,15,16,18,21}$ and HDL cholesterol $^{8,15,17,18,21-23}$ differed minimally with effect of time since last meal. Non HDL cholesterol $^{8,10,11,13,16,24}$ is also differed statistically insignificant. Recent studies suggest non HDL cholesterol is a better predictor for cardiovascular risk than LDL because it includes all Apo-B containing atherogenic lipoproteins. And it can be measure in nonfasting state s,10,11,13,16,24 $^{\text {. We }}$ measured direct LDL which differed insignificantly from fasting direct LDL $^{8,13,22,23,25,26,39}$. Calculated LDL can underestimate after meal as elevated triglycerides in Friedewald formula (LDLc $=$ TC - HDLc $\mathrm{TG} / 5)$. Increases in triglycerides were likely attributable directly to fat intake. And recent studies suggest nonfasting or postprandial 
hypertriglyceridemia significant risk factor for atherosclerosis or cardiovascular disease Postprandial or nonfasting hypertriglyceridemia should be treated ${ }^{33}$. Therefore the ideal diagnostic may be a non-fasting lipid profile and a separate, direct LDL test ${ }^{39}$.

\section{Conclusion}

In our study level of lipids differed minimally in nonfasting, probably because most people consume much less fat at ordinary meal than during a fat tolerance test which includes $1 \mathrm{gm}$ fat per $\mathrm{kg}$ body weight. Total cholesterol, HDL cholesterol and non HDL cholesterol is differed statistically insignificant. We measured direct LDL which differed insignificantly from fasting direct LDL. According to Friedewald formula $(\mathrm{LDLc}=\mathrm{TC}-\mathrm{HDLc}-\mathrm{TG} / 5)$ post meal calculated LDL will be underestimated as elevated level of triglycerides. In our study triglycerides were higher in nonfasting and recent studies suggest nonfasting or postprandial hypertriglyceridemia is a significant risk factor for atherosclerosis. From above findings we conclude that nonfasting blood draws may be highly effective and practical for lipid profile testing in diabetic patients.

\section{Recommendations}

- Lipid profile can be done in nonfasting state in diabetics and it is more practical and more feasible as we are in nonfasting state during maximum hours of day.

- LDL should be done by direct method as in nonfasting state increased triglycerides can underestimate the calculated LDL by Friedewald formula.

- Non HDL cholesterol can be measured in nonfasting state. More recently this is studied for better predictor of cardiovascular risk than LDL because it includes all Apo-B containing atherogenic lipoproteins.

- Future research should focus on studies reducing the levels of nonfasting triglycerides and thus remnant lipoprotein cholesterol in an attempt to reduce the risk of cardiovascular disease and death further than that currently obtained by reducing mainly LDL cholesterol levels.

- Furthermore the results also highlight the need for randomized double blind trials of new and established drugs to reduce nonfasting triglycerides and remnant lipoprotein cholesterol, with the ultimate aim of reducing risk of cardiovascular disease and early death.

\section{Index of References}

1. Libby P. The pathogenesis, prevention and treatment of atherosclerosis. In: Longo DL, Fauci AS, Kasper DL, Hauser SL, Jameson JL, Loscalzo J, editors. Harrison's Principles of Internal Medicine. 18th Ed. Vol- 2. USA: McGraw-Hill 2012; Chapter 241: pp 1983-91.

2. Powers AC. Diabetes Mellitus. In: Longo DL, Fauci AS, Kasper DL, Hauser SL, Jameson JL, Loscalzo J, editors. Harrison's Principles of Internal Medicine. 18th Ed. Vol- 2. USA: McGraw-Hill 2012; Chapter 344: pp 2968-3009.

3. Bae JH, Schwemmer M, Lee LK, Lee HJ, Park KR, Kim KY et al. Postprandial hypertriglyceridemia induced endothelial dysfunction in healthy subjects is independent of lipid oxidation. Int $\mathrm{J}$ Cardiol 2003; 87:259-67.

4. Plotnick GD, Corretti MC, Vogel RA. Effect of antioxidant vitamins on the transient impairment of endothelium dependent brachial artery vasoactivity following a single high fat meal. Jam Med Assoc 1997; 278:1682-6.

5. Kugiyama K, Doi H, Motoyama $T$. Association of remnant lipoprotein levels with impairment of endothelium dependent vasomotor function in human coronary arteries. Circulation 1998; 97:2519-26. 
6. Nordestgaard BG, Langsted A, Freiberg JJ. Nonfasting hyperlipidemia and cardiovascular disease. Curr Drug Targets 2009; 10:328-35.

7. Kannel WB, Vasan RS. Triglycerides as vascular risk factors: new epidemiologic insights. Curr Opin Cardiol 2009; 24:34550.

8. Alsaran K, Sabry A, Shaheen N. Is non fasting non-high-density lipoprotein cholesterol adequate for lipid management in Saudi hemodialysis patients? Jnrt 2009; 2:1-17.

9. Lee SH, Lee BW, Won HK, Moon JH, Kim KJ, Kang ES et al. Postprandial triglyceride is associated with fasting triglyceride and HOMA-IR in Korean subjects with type 2 diabetes. Diabetes Metab J 2011; 35:404-10.

10. Desmeules S, Arcand-Bossé JF, Bergeron J, Douville P, Agharazii M. Nonfasting non-high-density lipoprotein cholesterol is adequate for lipid management in hemodialysis patients. Am J Kidney Dis 2005; 45:1067-72

11. Kimak E, Ksiazek A, BaranowiczGaszczyk I, Solski J. Disturbed lipids, lipoproteins and triglyceride-rich lipoproteins as well as fasting and nonfasting non-high-density lipoprotein cholesterol in post-renal transplant patients. Ren Fail 2007; 29:705-12.

12. Mora S, Rifai N, Buring JE, Ridker PM. Fasting compared with nonfasting lipids and apolipoproteins for predicting incident cardiovascular events. Circulation 2008; 118:993-1001.

13. Dungan KM, Guster T, Dewalt DA, Buse JB. A comparison of lipid and lipoprotein measurements in the fasting and nonfasting states in patients with type 2 diabetes. Curr Med Res Opin 2007; 23:2689-95

14. Schaefer EJ, Audelin MC, Mcnamara JR, Shah PK, Tayler T, Daly JA et al.
Comparison of fasting and postprandial plasma lipoproteins in subjects with and without coronary heart disease. Am J Cardiol 2001; 88:1129-33.

15. Craig SR, Amin RV, Russell DW, Paradise NF. Blood cholesterol screening influence of fasting state on cholesterol results and management decision. J Gen Intern Med 2000; 15:395-9.

16. Langsted A,Freiberg JJ, Nordestgaard BG. Fasting and non fasting lipid levels: influence of normal food intake on lipids, lipoproteins, apolipoproteins, and cardiovascular risk prediction. Circulation 2008; 118:2047-56.

17. Wilder LB, Bachorik PS, Finney CA, Moy TF, Becker DM. The effect of fasting status on the determination of low-density and high-density lipoprotein cholesterol. Am J Med 1995; 99:374-7.

18. Sidhu D, Naugler C. Fasting time and lipid levels in a community-based population: a cross-sectional study. Arch Intern Med 2012; 172:1707-10.

19. Steiner MJ, Skinner AC, Perrin EM. Fasting might not be necessary before lipid screening: a nationally representative cross- sectional study. Paediatrics 2011; 128:463-70.

20. Van Dieren S, Nöthlings U, Van Der Schouw YT, Spijkerman AMW, Rutten GEHM, Van Der ADL et al. Non-fasting lipids and risk of cardiovascular disease in patients with diabetes mellitus. Diabetologia 2011; 54:73-7.

21. Folsom AR, Kuba K, Leupker RV, Jacobs DR, Frantz ID JR. Lipid concentrations in serum and EDTA-treated plasma from fasting and nonfasting normal persons, with particular regard to high-density lipoprotein cholesterol. Clin Chem 1983; 29:505-8.

22. Kim M, Suk J, Kim H, Jung H, Kim T, Park J. Post-prandial lipid levels for assessing target goal achievement in type 2 
diabetic patients taking statin. J Korean Med Sci 2010; 25:387-92.

23. Langsted A, Nordestgaard BG. Nonfasting lipids, lipoproteins and apolipoproteins in individuals with and without diabetes: 58434 individuals from the Copenhagen general population study. Clin Chem 2011; 57:482-9.

24. Weiss R, Harder M, Rowe J. The relationship between nonfasting and fasting lipid measurements in patients with or without type 2 diabetes mellitus receiving treatment with 3-hydroxy-3methylglutaryl-coenzyme a reductase inhibitors. Clin Ther 2003; 25:1490-7.

25. De Ferranti S, Shapiro D, Markowitz R, Neufeld E, Rifai N, Bernstein $H$. Nonfasting low-density lipoprotein testing: utility for cholesterol screening in pediatric primary care. Clin Pediatr (Phila) 2007; 46:441-5.

26. Harris N, Neufeld EJ, Newburger JW, Ticho B, Baker A, Ginsburg GS et al. Analytical performance and clinical utility of a direct LDL-cholesterol assay in a hyperlipidemic pediatric population. Clin Chem 1996; 42:1182-8.

27. Suryabhan LL, Chandrashekhar MI, Ratnendra RS, Prerna DN. A comparative study on the fasting and the postprandial dyslipidaemia in type 2 diabetes mellitus. $\mathbf{J}$ Clin Diagn Res 2013; 7:627-30.

28. Fu ZF, Liu ML. Postprandial changes of blood lipid after ordinary Chinese diet and the influencing factors thereof. Zhonghua Yi Xue Za Zhi 2009; 89:260-2

29. Eberly LE, Stamler J, Neaton JD. Multiple risk factor intervention trial research groups. Relation of triglyceride levels, fasting and nonfasting, to fatal and nonfatal coronary heart disease. Arch Intern Med 2003; 163:1077-83.

30. Cohn JS, Mcnamara JR, Schaefer EJ. Lipoprotein cholesterol concentrations in the plasma of human subjects as measured in the fed and fasted states. Clin Chem 1988; 34:2456-9.

31. Nordestgaard BG, Freiberg JJ. Clinical relevance of non-fasting and postprandial hypertriglyceridemia and remnant cholesterol. Curr Vasc Pharmacol 2011; 9:281-6

32. Lindman AS, Veierød MB, Tverdal A, Pedersen JJ, Selmer R. Nonfasting triglycerides and risk of cardiovascular death in men and women from the Norwegian counties study. Eur J Epidemiol 2010; 25:789-98.

33. Kolovou GD, Mikhailidis DP, Kovar J, Lairon D, Nordestgaard BG, Ooi TC et al. Assessment and clinical relevance of nonfasting and postprandial triglycerides: an expert panel statement. Curr Vasc Pharmacol 2011; 9:258-70.

34. Langsted A, Freiberg JJ, Tybjaerg-Hansen A, Schnohr P, Jensen GB, Nordestgaard BG. Nonfasting cholesterol and triglycerides and association with risk of myocardial infarction and total mortality; the Copenhagen city heart study with 31 years of follow up. J Intern Med 2011; 270:65-75.

35. Freiberg JJ, Tybjaerg-Hansen A, Jensen JS, Nordestgaard BG. Nonfasting triglycerides and risk of ischemic stroke in the general population. Jama 2008; 300:2142-52.

36. Stalenhoef AF, De Graaf J. Association of fasting and non fasting serum triglycerides with cardiovascular disease and the role of remnant like lipoproteins and small dense LDL. Curr Opin Lipidol 2008; 19:355-61.

37. Bansal S, Buring JE, Rifai N, Mora S, Sacks FM, Ridker PM. Fasting compared with non fasting triglycerides and risk of cardiovascular events in women. Jama 2007; 298:309-16.

38. Nordestgaard BG, Benn M, Schnohr P, Tybjaerg-Hansen A. Nonfasting triglycerides and risk of myocardial 
infarction, ischemic heart disease, and death in men and women. Jama 2007; 298:299-308.

39. Mark Deeg. Who, what, and when to test patients for dyslipidemias. Lipid Topics.

40. Iso $H$, Naito $Y$, Sato $S$, Kitamura A, Okamura T, Sankai $\mathrm{T}$ et al. Serum triglycerides and risk of coronary heart disease among Japanese men and women. Am J Epidemiol 2001; 153:490-9.

41. Coppack SW. Postprandial lipoproteins in non-insulin-dependent diabetes mellitus. Diabet Med 1997;14 Suppl 3:S67-74
42. Stampfer MJ, Krauss RM, Ma J, Blanche PJ, Holl LG, Sacks FM et al. A prospective study of triglyceride level, low density lipoprotein particle diameter, and risk of myocardial infarction. Jama 1996; 276:882-8.

43. Patsch JR, Miesenböck G, Hopferwieser T, Mühlberger V, Knapp E, Dunn JK et al. Relation of triglyceride metabolism and coronary artery disease: Studies in the postprandial state. Arterioscler Thromb 1992; 12:1336-45.

\section{LIST OF ABBREVIATION USED}

\begin{tabular}{|c|c|l|}
\hline $\begin{array}{c}\text { S } \\
\text { no. }\end{array}$ & & \\
\hline 1. & $\%$ & Percentage \\
\hline 2. & $<$ & Less than \\
\hline 3. & $>$ & More than \\
\hline 4. & Apo & Apo lipoprotein \\
\hline 5. & ATP & Adult Treatment Panel \\
\hline 6. & DM & Diabetes Mellitus \\
\hline 7. & FBS & Fasting Blood Sugar \\
\hline 8. & HbA1c & Glycosylated Haemoglobin \\
\hline 9. & HDL c & High Density Lipoprotein Cholesterol \\
\hline 10 & LDL c & Low Density Lipoprotein Cholesterol \\
\hline 11 & NCEP & National Cholesterol Education Program \\
\hline 12 & PPBS & Post Prandial Blood Sugar \\
\hline 13 & TC/CH & Total Cholesterol \\
\hline 14 & TG & Triglycerides \\
\hline 15 & VLDL c & Very Low Density Lipoprotein Cholesterol \\
\hline 16 & CHD & Coronary Heart Disease \\
\hline 17 & R & Nonfasting or Random \\
\hline 18 & F & Fasting \\
\hline & & \\
\hline
\end{tabular}

